\title{
Medical management of brain metastases from lung cancer (Review)
}

\author{
RYUYA YAMANAKA \\ Research Center of Innovative Cancer Therapy, Kurume University School of Medicine, \\ 67 Asahimachi, Kurume, Fukuoka 830-0011, Japan
}

Received June 11, 2009; Accepted August 3, 2009

DOI: 10.3892/or_00000564

\begin{abstract}
Brain metastases are a frequent complication in patients with lung cancer and a significant cause of morbidity and mortality. The prognosis of these patients is poor. Medical therapies for brain metastases are neither wellstudied nor established. This review analyzes the impact of medical treatment on survival by reviewing recent articles of the management of brain metastases from lung cancer patients. Chemotherapy for brain metastases from lung cancer is effective for both small cell and non-small cell lung cancer. Since brain metastases are part of systemic progression, chemotherapy should always be considered for the therapeutic management of brain metastases. Available data and response rates in lung cancer patients indicated that medical treatment for the management of brain metastases should be part of a multimodality treatment.
\end{abstract}

\section{Contents}

1. Introduction

2. Non-small cell lung cancer (NSCLC)

3. Small cell lung cancer (SCLC)

4. Discussion

\section{Introduction}

Brain metastases are a frequent complication in patients with lung cancer and a significant cause of morbidity and mortality. Brain metastases are found in about $10-25 \%$ of patients at the time of diagnosis, and approximately $40-50 \%$ of all patients with lung cancer develop brain metastases during the course of their disease, with greater frequency at autopsy (approximately 50\%) than predicted from the presence of symptoms

Correspondence to: Dr Ryuya Yamanaka, Research Center of Innovative Cancer Therapy, Kurume University School of Medicine, 67 Asahimachi, Kurume, Fukuoka 830-0011, Japan

E-mail: ryaman@med.kurume-u.ac.jp

Key words: brain metastases, chemotherapy, lung cancer, nonsmall cell carcinoma, small cell carcinoma
(1). The incidence of brain metastasis is increasing mainly due to longer patient survivals resulting from newer treatment modalities. Most patients with lung cancer metastatic to the brain have multiple lesions (2). Brain metastases are usually associated with poor outcomes and shortened survival of 36 months. Standard treatment options include symptomatic therapy with corticosteroids and whole-brain radiotherapy (WBRT) (3), and more aggressive approaches such as surgery or radiosurgery are indicated in a subset of patients $(4,5)$. Surgical resection of accessible brain metastases combined with postoperative WBRT is the management of choice for a single metastasis (6). However, radiosurgery for brain metastases produces high rates of tumor control similar to the rates obtained by excisional surgery (7). Patients with multiple brain metastases are commonly treated with WBRT for the palliation of symptoms (8). The role of radiosurgery for multiple brain metastases is less clear, but it can be effective (9). The poor outcomes and relapses following WBRT alone indicate a need for new therapeutic options. Generally, poor prognosis occurs not from cerebral problems, but from extracranial metastases, and death is caused by systemic disease combined with the neurological condition (10). However, treatment with systemic chemotherapy is controversial because chemotherapeutic agents may not cross the blood-brainbarrier (BBB) and therefore are less effective against central nervous system (CNS) disease than against extracranial, systemic disease. However, the BBB is partially disrupted in brain metastases (11) and similar concentrations of chemotherapeutic agents are found in intracerebral and extracerebral tumors (5). Brain metastases resulting from both non-small cell (NSCLC) and small cell lung cancer (SCLC) are susceptible to systemic chemotherapy, and cerebral response rates up to $50 \%$ were observed even in second-line treatment of NSCLC and SCLC $(1,10,11)$. Still, medical therapies for brain metastases are neither well-studied nor established. Here, the impact of medical treatment on survival is analyzed by reviewing recent articles and providing recommendations for the management of patients with brain metastases from lung cancer.

\section{Non-small cell lung cancer (NSCLC)}

NSCLC accounts for $\sim 75 \%$ of lung cancer cases, with the majority of patients having inoperable, locally advanced or metastatic disease at the time of diagnosis, reflected in the 
Table I. Front-line chemotherapy for non-small cell lung cancer.

\begin{tabular}{llcccccc}
\hline $\begin{array}{l}\text { Author } \\
\text { (Refs.) }\end{array}$ & \multicolumn{1}{c}{ Regimen } & $\begin{array}{c}\text { No. of } \\
\text { patients }\end{array}$ & $\begin{array}{c}\text { Study } \\
\text { design }\end{array}$ & $\begin{array}{c}\text { Response } \\
\text { rate }(\%)\end{array}$ & $\begin{array}{c}\text { Disease } \\
\text { stabilization (\%) }\end{array}$ & $\begin{array}{c}\text { mPFS } \\
\text { (month) }\end{array}$ & $\begin{array}{c}\text { OS } \\
\text { (month) }\end{array}$ \\
\hline Cotto et al $(15)$ & CDDP, Fotemustine & 31 & Phase II & 23 & 51.6 & 5 & 4 \\
Malacarne et al (16) & CBDCA, VP-16 & 18 & Phase II & 17 & 39 & n.d. & 7.5 \\
Minotti et al (17) & CDDP, Teniposide & 23 & Phase II & 35 & 65 & 7 & 5 \\
Franciosi et al $(18)$ & CDDP, VP-16 & 43 & Phase II & 30 & 65 & 4 & 8 \\
Fujita et al (19) & CDDP, IFOS, CPT-11 & 28 & Phase I/II & 50 & 96 & 4.6 & 12 \\
Robinet et al $(20)$ & CDDP, VNR & 76 & Phase III & 27 & n.d. & 3.2 & 6 \\
Bernardo et al $(21)$ & CBDCA, VNR, GEM & 22 & Phase II & 45 & 85 & 6.2 & 8.2 \\
Cortes et al (22) & CDDP, Paclitaxel & 26 & Phase II & 38 & 69 & 3.2 & 5.3 \\
\hline
\end{tabular}

CBDCA, carboplatin; CDDP, cisplatin; CPT-11, irinotecan; GEM, gemcitabine; IFOS, ifosfamide; mOS, median overall survival; mPFS, median progression-free survival; n.d., not determined; VNR, vinorelbine; VP-16, etoposide.

Table II. Phase II studies of gefitinib for non-small cell lung cancer.

\begin{tabular}{lcccccc}
\hline $\begin{array}{l}\text { Author } \\
\text { Refs.) }\end{array}$ & $\begin{array}{c}\text { No. of } \\
\text { patients }\end{array}$ & $\begin{array}{c}\text { Study } \\
\text { design }\end{array}$ & $\begin{array}{c}\text { Previous WBRT/ } \\
\text { Chemo }(\%)\end{array}$ & $\begin{array}{c}\text { Response } \\
\text { rate }(\%)\end{array}$ & $\begin{array}{c}\text { Disease } \\
\text { stabilization }(\%)\end{array}$ & $\begin{array}{c}\text { mPFS } \\
(\text { month })\end{array}$ \\
\hline Ceresoli et al (34) & 41 & Phase II & $43.9 / 90.2$ & 9.7 & 26.8 & 3 \\
Chiu et al (32) & 76 & Phase II & n.d./84.2 & 33.3 & 63.2 & 5 \\
Wu et al (33) & 40 & Phase II & $65 / 100$ & 32 & 77 & 9.9 \\
\hline
\end{tabular}

Chemo, chemotherapy; mOS, median overall survival; mPFS, median progression-free survival; n.d., not determined; WBRT, whole brain radiotherapy.

low 5-year survival rate for all stages (currently 13\%) (12). Despite two decades of cisplatin-based chemotherapy of advanced NSCLC, the survival benefit remains modest (13). New chemotherapy combinations have minimal impact on survival compared with older regimens, with overall response rates of $\sim 30 \%$, median survival benefits of 8-9 months, and 1 -year survival rates of $\sim 30 \%$ (14). New therapies are required that are effective against locally advanced or metastatic NSCLC.

\section{Front-line chemotherapy}

Many chemotherapeutic regimens have been tested in phase II or III trials for the treatment of brain metastases arising from NSCLC (Table I). There are 8 larger reports (15-22) with more than 10 patients, published from 1994 to 2008 in English, on front-line chemotherapy of brain metastases from NSCLC. In patients with NSCLC, $17-50 \%$ of patients with previously untreated brain metastases responded to a combination of cisplatin plus fotemustine; carboplatin plus etoposide; cisplatin plus teniposide; cisplatin plus etoposide; cisplatin plus ifosfamide, CPT-11; cisplatin plus vinorelbine; carboplatin plus vinorelbine, gemcitabine; cisplatin plus paclitaxel. Systemic disease activity correlates well with activity against brain metastases, but overall survival (OS) is still 4-12 months.

\section{Second-line chemotherapy}

Epidermal growth factor receptor tyrosine kinase inhibitor. The epidermal growth factor receptor (EGFR) is expressed in a variety of tumors, including NSCLC (23), and elevated EGFR expression is associated with a poor prognosis in lung cancer patients (24). Several EGFR-targeted agents have been developed, including gefitinib (ZD1839; Iressa) and erlotinib (OSI-774; Tarceva), an orally active anilinoquinazoline compound that inhibits EGFR tyrosine kinase activity (25). In two large, well-designed phase II clinical trials, refractory patients with NSCLC experienced overall response rates of $11.8-18.4 \%$, median survival benefits of 6.5-7.6 months, and 1-year survival rates of $29-35 \%(26,27)$, with encouraging response rates in select patients (women, non-smokers, patients with adenocarcinoma, and specific EGFR mutations in the kinase domain) (26-31). Although targeting EGFR-associated tyrosine kinase with gefitinib and erlotinib results in durable responses in some patients, the activity of these drugs against brain metastases has been poorly documented so far.

Gefitinib. Phase II studies of gefitinib on brain metastases from NSCLC indicated objective responses occur in $33 \%$ of patients (Asia) $(32,33)$ or $9.7 \%$ of patients (Europe) (34) (Table II). In comparison, WBRT with 30-40 Gy for brain metastases from NSCLC results in objective responses in 38- 
Table III. Erlotinib treatment for non-small cell lung cancer.

\begin{tabular}{|c|c|c|c|c|c|c|c|}
\hline $\begin{array}{l}\text { Author } \\
\text { (Refs.) }\end{array}$ & $\begin{array}{c}\text { Age/ } \\
\text { Gender }\end{array}$ & Histology & $\begin{array}{c}\text { Race/ } \\
\text { Smoking } \\
\text { status }\end{array}$ & $\begin{array}{c}\text { Previous } \\
\text { WBRT/ } \\
\text { Chemo }\end{array}$ & $\begin{array}{c}\text { Brain } \\
\text { response }\end{array}$ & $\begin{array}{c}\text { Extracranial } \\
\text { response }\end{array}$ & $\begin{array}{c}\text { Response } \\
\text { duration } \\
\text { (month) }\end{array}$ \\
\hline Lai et al (41) & $55 / \mathrm{F}$ & $\mathrm{ADE}$ & Chinease/non-smoker & $+/+$ & $\mathrm{CR}$ & n.d. & $>6$ \\
\hline Popat et al (42) & $42 / \mathrm{F}$ & $\mathrm{ADE}$ & Caucasian/non-smoker & $+/+$ & PR & PD & n.d. \\
\hline Chang et al (43) & $41 / \mathrm{M}$ & $\mathrm{ADE}$ & Taiwanese/smoker & $+/+$ & PR & PR & 18 \\
\hline Gounant et al (44) & $32 / \mathrm{F}$ & $\mathrm{ADE}$ & Chinease/non-smoker & $+/+$ & PR & PD & 5,2 (rechallenge) \\
\hline Fekrazad et al (45) & $60 / \mathrm{F}$ & $\mathrm{ADE}$ & American/non-smoker & $+/-$ & CR & PR & $>8$ \\
\hline \multirow[t]{2}{*}{ Von Pawel et al (46) } & $40 / \mathrm{F}$ & $\mathrm{ADE}$ & n.d./smoker & $+/+$ & PR & SD & 9 \\
\hline & $63 / \mathrm{F}$ & $\mathrm{ADE}$ & n.d./non-smoker & $+/+$ & CR & PR & $>9$ \\
\hline Altavilla et al (47) & $61 / \mathrm{M}$ & $\mathrm{ADE}$ & Italian/smoker & $+/+$ & CR & PR & $>11$ \\
\hline Ruppert et al (48) & $27 / \mathrm{M}$ & $\mathrm{ADE}$ & n.d./non-smoker & $+/+$ & PR & PD & n.d. \\
\hline
\end{tabular}

ADE, adenocarcinoma; Chemo, chemotherapy; CR, complete response; F, female; M, male; n.d., not determined; PD, progressive disease; PR, partial response; $\mathrm{SD}$, stable disease; WBRT, whole brain radiotherapy.

$45 \%$ of patients $(35,36)$. Gefitinib is well-tolerated, mostly with grade $1 / 2$ skin rashes. The severity of skin toxicity was tightly associated with tumor response and patient survival (32). Gefitinib was most effective at treating brain metastases in patients with EGFR mutations in the tyrosine kinase domain (deletion mutation in two patients and a point mutation in one patient) in one study (37). However, this analysis was performed using tissue samples from primary lung cancer and not from metastatic brain lesions. Yokouchi et al (38) reported that some patients who experienced disease progression after responding to gefitinib were sensitive to gefitinib re-administration after temporary cessation of gefitinib and other treatments. Patients may still be expected to have prolonged survival if they once responded to gefitinib and then underwent various subsequent treatments followed by re-administration of gefitinib. These findings might provide valuable information for the management of gefitinibresponders. Although the survival benefit is controversial, gefitinib may also be useful for the treatment of carcinomatous meningitis from NSCLC to improve neurological dysfunction $(39,40)$. Thus, gefitinib has therapeutic potential for palliative therapy in patients with brain metastases.

Erlotinib. Erlotinib treatment of brain metastases from NSCLC has been reported in 9 cases (41-48) (Table III). Three Asians, 6 females and non-smokers were histologically confirmed as adenocarcinoma in the primary site. The main adverse events were Grade 1 skin rashes. Six patients had responses longer than 6 months. Erlotinib responses are higher in patients with a somatic mutation in EGFR or a point mutation in the activation loop of the kinase domain $(28,49)$. An EGFR L858R point mutation was identified in 3 patients and an EGFR exon 19 deletion in 2 patients. Three patients showed a response to erlotinib after gefitinib failure; two of these had an in-frame deletion in exon 19 of EGFR. Although gefitinib failure may result from cross-resistance to other EGFR tyrosine kinase inhibitors (EGFR-TKI), these cases suggest that re-challenging patients with EGFR-TKI may be beneficial. In addition, two patients with intracranial lesions responded to erlotinib treatment although extra-cranial lesion progressed. In the case of Ruppert et al (48), a secondary T790M mutation associated with resistance to EGFR-TKI was found in the liver biopsy. Erlotinib was reintroduced and produced quick neurological improvement, even though the extra-cranial disease remained resistant to erlotinib. These cases also highlight the oligoclonal nature of NSCLC and its differential sensitivity to EGFR-TKIs, in that extra-cranial disease was resistant to erlotinib both initially and on re-challenge. Persistent cerebral TKI sensitivity should be considered in patients presenting with a CNS relapse after stopping EGFR-TKI, even with a T790M resistant mutation in non-cerebral metastases. In addition, erlotinib should be considered for treatment of intra-cranial disease.

Temozolomide. Temozolomide is an orally administered prodrug that is converted spontaneously to the active alkylating agent, monomethyl triazenoimidazole carboxamide, at physiologic $\mathrm{pH}$, crosses the $\mathrm{BBB}$, and has antitumor activity against malignant glioma, melanoma, NSCLC, and carcinoma of the ovary and colon (50) (Table IV). CNS concentrations reach $\sim 30-40 \%$ of plasma levels, achieving therapeutic concentrations in the brain (51), and clearance of temozolomide is unaffected by co-administration with anticonvulsants, anti-emetics, or dexamethasone $(50,51)$. The dose-limiting toxicity is non-cumulative myelosuppression that rarely requires treatment delays or dose reductions. In patients with newly-diagnosed brain metastases or with progression after radiotherapy, temozolomide produces objective response rates between 5 and $10 \%$ (52-58) and is well-tolerated.

Temozolomide plus other chemotherapeutic agents. Preclinical experiments and early clinical studies in other malignancies indicate that temozolomide may have additive or synergistic effects when used with other chemotherapeutic agents $(56,57)$. In addition, its minimal toxicity allows for the combination of temozolomide with gemcitabine, gemcitabine/cisplatin, or 
Table IV. Temozolomide treatment for non-small cell lung cancer.

\begin{tabular}{|c|c|c|c|c|c|c|c|c|}
\hline $\begin{array}{l}\text { Author } \\
\text { (Refs.) }\end{array}$ & Regimen & $\begin{array}{c}\text { No. of } \\
\text { patients }\end{array}$ & $\begin{array}{l}\text { Study } \\
\text { design }\end{array}$ & $\begin{array}{c}\text { Previous } \\
\text { WBRT/ } \\
\text { Chemo }(\%)\end{array}$ & $\begin{array}{c}\text { Response } \\
\text { rate }(\%)\end{array}$ & $\begin{array}{c}\text { Disease } \\
\text { stabilization } \\
(\%)\end{array}$ & $\begin{array}{c}\text { mPFS } \\
\text { (month) }\end{array}$ & $\begin{array}{c}\text { OS } \\
\text { (month) }\end{array}$ \\
\hline Giorgio et al (52) & TMZ & 30 & Phase II & $100 / 100$ & 10 & 20 & 3.6 & 6 \\
\hline Kouroussis et al (53) & TMZ & 12 & Phase II & n.d./100 & 8.3 & 25 & n.d. & n.d. \\
\hline Abrey et al (54) & TMZ & 22 & Phase II & 100/n.d. & 9 & 45 & n.d. & n.d. \\
\hline Christodoulou et al (55) & TMZ & 12 & Phase II & 100/n.d. & 8 & n.d. & n.d. & n.d. \\
\hline
\end{tabular}

TMZ, temozolomide; Chemo, chemotherapy; mOS, median overall survival; mPFS, median progression-free survival; n.d., not determined; WBRT, whole brain radiotherapy.

Table V. Chemotherapy plus whole-brain irradiation for non-small cell lung cancer.

\begin{tabular}{|c|c|c|c|c|c|c|c|c|}
\hline $\begin{array}{l}\text { Author } \\
\text { (Refs.) }\end{array}$ & $\begin{array}{l}\text { Chemotherapy } \\
\text { regimen }\end{array}$ & $\begin{array}{c}\text { No. of } \\
\text { patients }\end{array}$ & $\begin{array}{l}\text { Study } \\
\text { design }\end{array}$ & $\begin{array}{c}\text { Previous } \\
\text { WBRT/ } \\
\text { Chemo }(\%)\end{array}$ & $\begin{array}{c}\text { Response } \\
\text { rate }(\%)\end{array}$ & $\begin{array}{c}\text { Disease } \\
\text { stabilization } \\
(\%)\end{array}$ & $\begin{array}{c}\text { mPFS } \\
\text { (month) }\end{array}$ & $\begin{array}{c}\text { OS } \\
\text { (month) }\end{array}$ \\
\hline Quantin et al (60) & CDDP, VNR, IFOS & 23 & Phase II & $0 / 0$ & 56 & 65 & n.d. & 7.6 \\
\hline Quantin et al (61) & High-dose IFOS & 16 & Phase II & n.d./n.d. & 25 & n.d. & n.d. & 13 \\
\hline Ma et al (62) & Gefitinib & 25 & Phase II & $0 / 0$ & 81 & 95.2 & 10 & 13 \\
\hline Addeo et al (63) & TMZ & 15 & Phase II & $44 / 74$ & 6.5 & 60 & 6 & 8.8 \\
\hline Cortot et al (64) & CDDP, TMZ & 50 & Phase II & 6/n.d. & 12 & 54 & 2.3 & 5 \\
\hline Robinet et al (20) & CDDP, VNR & 85 & Phase III & $0 / 0$ & 28 & n.d. & 2.7 & 5.2 \\
\hline
\end{tabular}

CDDP, cisplatin; Chemo, chemotherapy; IFOS, ifosfamide; mOS, median overall survival; mPFS, median progression-free survival; n.d., not determined; TMZ, temozolomide; VNR, vinorelbine; WBRT, whole brain radiotherapy.

gemcitabine/vinorelbine in NSCLC patients to produce dramatic cerebral responses $(58,59)$. The combination of temozolomide with other chemotherapeutic agents represents a promising strategy for treating brain metastases.

\section{Chemotherapy plus whole-brain irradiation}

Combining chemotherapy with brain radiotherapy is attractive because chemotherapy is active against both primary tumors and brain metastases, and because chemotherapy may act as a radiosensitizer. Two studies have compared randomized chemotherapy alone with chemotherapy/WBRT (Table V). Quantin et al (60) reported a phase II study of radiotherapy plus vinorelbine, ifosfamide, and cisplatin chemotherapy in patients with brain metastases of NSCLC. The response rate was $56 \%$ and median survival was 7.6 months. The same author also reported a phase II study with concomitant brain radiotherapy and high-dose ifosfamide in brain relapses (61). Median survival was 13 months. Myelosuppression was the main toxic effect, but remained manageable and no toxic deaths occurred. The high response rate for brain lesions and improvement in neurological symptoms deserves further exploration.

Ma et al (65) found that treatment with concomitant gefitinib and WBRT was well-tolerated, with significant improvement of neurological symptoms in a Chinese population with brain metastases from NSCLC. Addeo et al (63) reported response rates of $6.5 \%$ using a combination of temozolomide and WBRT. Cortot et al (64) reported response rates of $12 \%$ with temozolomide, cisplatin, and WBRT. A randomized phase II study evaluated the efficacy of concurrent temozolomide and radiotherapy versus radiotherapy alone in 58 patients with previously untreated brain metastases from different solid tumors (31 patients had NSCLC) (65). The temozolomide group showed significant improvements in cerebral response rate (96 vs. 67\%), and temozolomide was safe and well-tolerated. However, overall survival rates and changes in neurological function were similar in both groups.

Robinet et al (20) reported a phase III study comparing the timing of WBRT, either before or after chemotherapy, and found a $28 \%$ response rate in 85 patients treated with cisplatin and vinorelbine in the early WBRT arm. The median survival in this arm was 5.2 months and median time to progression (TTP) was 2.1 months. Radiotherapy timing did not change survival time. Thus, for NSCLC, WBRT should be added to initial chemotherapy if there is no treatment response.

\section{Small cell lung cancer (SCLC)}

The brain is the most common metastatic site in SCLC, and is usually fatal. Approximately $18-25 \%$ of SCLC patients have brain metastases already at diagnosis, and an additional 
Table VI. Front-line chemotherapy for small cell lung cancer.

\begin{tabular}{|c|c|c|c|c|c|c|c|}
\hline $\begin{array}{l}\text { Author } \\
\text { (Refs.) }\end{array}$ & Regimen & $\begin{array}{c}\text { No. of } \\
\text { patients }\end{array}$ & $\begin{array}{l}\text { Study } \\
\text { design }\end{array}$ & $\begin{array}{c}\text { Response } \\
\text { rate }(\%)\end{array}$ & $\begin{array}{c}\text { Disease } \\
\text { stabilization } \\
(\%)\end{array}$ & $\begin{array}{c}\text { mPFS } \\
\text { (month) }\end{array}$ & $\begin{array}{c}\text { OS } \\
\text { (month) }\end{array}$ \\
\hline Lee et al (70) & CTX, DX, VCR, VP-16 & 11 & Phase II & 82 & 91 & 6 & 8.5 \\
\hline Twelves et al (71) & CTX, VP-16, VCR & 25 & Retrospective & 53 & n.d. & 5.5 & 8.5 \\
\hline Kristjansen et al (72) & CDDP, VP-16, VCR & 21 & Phase II & 52 & 57 & 4.5 & 3.7 \\
\hline Seute et al (73) & CTX, DX, VP-16 & 22 & Phase II & 27 & 50 & n.d. & n.d. \\
\hline
\end{tabular}

CTX, cyclophosphamide; DX, doxorubicin; mOS, median overall survival; mPFS, median progression-free survival; n.d., not determined; VCR, vincristine; VP-16, etoposide.

Table VII. Second-line chemotherapy for small cell lung cancer.

\begin{tabular}{|c|c|c|c|c|c|c|c|}
\hline $\begin{array}{l}\text { Author } \\
\text { (Refs.) }\end{array}$ & Regimen & $\begin{array}{l}\text { No. of } \\
\text { patients }\end{array}$ & $\begin{array}{l}\text { Study } \\
\text { design }\end{array}$ & $\begin{array}{l}\text { Response } \\
\text { rate }(\%)\end{array}$ & $\begin{array}{c}\text { Disease } \\
\text { stabilization }(\%)\end{array}$ & $\begin{array}{l}\text { mPFS } \\
\text { (month) }\end{array}$ & $\underset{\text { (month) }}{\text { OS }}$ \\
\hline Postmus et al (74) & HD-VP-16 & 23 & Phase II & 43 & 52 & n.d. & 8 \\
\hline Groen et al (75) & CBDCA & 20 & Phase II & 40 & 60 & 2 & 4 \\
\hline Postmus et al (76) & Teniposide & 80 & Phase II & 33 & 47.5 & 4.8 & 2.9 \\
\hline Schuette et al (77) & Topotecan & 22 & Phase II & 50 & 82 & n.d. & 6 \\
\hline Postmus et al (78) & Teniposide & 60 & Phase III & 22 & 43 & 4.5 & 3.2 \\
\hline Korfel et al (79) & Topotecan & 30 & Phase II & 33 & 60 & 3.1 & 3.6 \\
\hline Chen et al (80) & CBDCA, CPT-11 & 15 & Phase II & 65 & 86 & n.d. & 6 \\
\hline
\end{tabular}

CBDCA, carboplatin; CPT-11, irinotecan; mOS, median overall survival; mPFS, median progression-free survival; n.d., not determined; HD-VP-16, high dose etoposide.

$50 \%$ will develop CNS involve-ment during their disease course (66-68). Although WBRT and corticosteroids are the treatment of choice, systemic chemotherapy may also have therapeutic value. Extracranial disease is almost always present in SCLC, and chemotherapy can treat both brain metastases and these other disease sites. Prophylactic cranial irradiation (PCI) for patients responsive to induction therapy markedly reduces the risk of CNS relapse and significantly improves survival $(68,69)$. Surgical treat-ment for solitary lesions or systemic chemotherapy for multi-focal brain metastases that are minimally symptomatic can be useful, particularly when these patients also have extracranial metastatic disease. Thus, systemic chemotherapy can complement WBRT for treatment of brain metastases in SCLC.

\section{Front-line chemotherapy}

There are 4 larger reports (70-73) with more than 10 patients, published from 1989 to 2008 in English, on front-line chemotherapy of brain metastases from SCLC (Table VI). The chemotherapeutic regimens, including cyclophosphamide, vincristine, etoposide, doxorubicin and cisplatin, produced response rates of $27-82 \%$ Thus, chemotherapy followed by radiation therapy may be first-line treatment for patients with systemic disease and asymptomatic brain metastases.

\section{Second-line chemotherapy}

SCLC relapse may also require systemic chemotherapy, which showed efficacy in 7 small phase II studies (74-80) with chemotherapy as salvage treatment after failing systemic chemotherapy and WBRT (Table VII). Response rates are generally lower and survival is decreased in patients who receive chemotherapy for brain metastases after failure following radiotherapy. Postmus et al (74) reported a response rate of $43 \%$ in the brain after high-dose etoposide. Groen et al (75) reported a response rate of $40 \%$ with carboplatin and Postmus et al (76) reported a response rate of $42 \%$ with a single agent, teniposide. The response rates of the primary tumor are not given in these reports. Chen et al (80) reported a high response rate of $65 \%$ with a combination of carboplatin and irinotecan. In an analysis by Schuette et al (77) and Korfel et al (79), response rates for brain metastases of 50 and $33 \%$, respectively, were achieved with topotecan. In both, the cerebral response rate was superior to the response rate of the primary tumor, probably because the intact BBB during the first treatment round protected tumor cells of the brain metastases. However, the severe adverse events associated with these regimens would be difficult to tolerate for pretreated patients who had already received radiation and multiple regimens of myelosuppressive chemotherapy. 
Treatment-related mortality was observed in 7 of 13 patients treated with high-dose etoposide (74) and in 8 of 80 patients treated with teniposide (76).

Temozolomide shows low response rates when used alone. Ebert et al (58) reported a case of a patient with SCLC with recurrent brain metastases who was treated with temozolomide and oral etoposide. This regimen was well-tolerated and resulted in dramatic, durable responses. Combining temozolomide with other chemotherapeutic agents represents a promising strategy for treating patients with brain metastases from SCLC.

\section{Chemotherapy plus whole-brain irradiation}

Postmus et al (78) reported a phase III study where 120 SCLC patients with brain metastases were randomized to receive teniposide with or without WBRT. Combined treatment produced a $57 \%$ response rate, and teniposide alone produced a $22 \%$ response rate. Combined treatment produced a longer TTP, but both regimens produced similar clinical responses outside the brain, median survival times (median survival 3.5 and 3.2 months, respectively) and symptomatic improvement. Further studies are needed to compare combinations of WBRT with chemotherapy.

\section{Discussion}

The impairment of physical, cognitive, and affective function that accompanies most brain metastases is highly distressing and can be seen as a 'loss' of the patient even before death. Improved treatment of overt brain metastases may have palliative value and eradication of microscopic brain disease may cure patients already cured in other sites. Assumptions about BBB penetration and chemotherapy resistance have limited the use of chemotherapy for treatment of brain metastases. Small, lipid-soluble molecules can penetrate the normal BBB barrier, but large, hydrophilic molecules cannot. Furthermore, high levels of the multidrug transporter, P-gp, are expressed in the endothelial cells of brain capillaries. P-gp actively prevents drugs from passing through the BBB (81). However, macroscopic metastases, relapsed disease, and radiation therapy can disrupt the BBB (82), as shown via magnetic resonance imaging (MRI) or computed tomography (CT) of intravenous contrast inside intracerebral lesions. In addition, the concentration of chemotherapy drugs, including platinum, is similar in intracerebral and extracerebral tumors (5). Cytostatics unable to penetrate the BBB produce comparable response rates for cerebral metastases and systemic disease, and adding BBB-penetrating drugs such as procarbazine, nitrosoureas, or methotrexate to a standard combination regimen did not improve the CNS relapse frequency $(83,84)$. The chemosensitivity of the primary tumor is the major determinant of the response to systemic treatment for brain metastases $(82,85)$, although asymptomatic brain metastases may have lower responses than systemic tumors to systemic chemotherapy (73).

Dexamethasone and enzyme-inducing anti-epileptic drugs (EIAEDs) can induce cytochrome p450 3A isoenzymes, including CYP3A4, which metabolizes chemotherapeutic agents $(86,87)$ including paclitaxel, irinotecan, vinorelbine, cyclophosphamide, doxorubicin, etoposide, ifosfamide, teniposide, erlotinib and gefitinib. Therefore, co-administration of EIAEDs or dexamethasone may increase the metabolism of chemotherapeutic agents, lower plasma concentrations, and reduce efficacy.

Response and survival rates are generally lower after chemotherapy for brain metastases following radiotherapy failure (75). Combination regimens also produce side effects that would be difficult to tolerate after radiation or multiple regimens of myelosuppressive chemotherapy. Oral agents such as gefitinib, erlotinib, and temozolomide were welltolerated even in pretreated patients, confirming their favorable adverse event profile. In a molecularly selected population with brain metastases, these agents can produce high response rates.

Brain metastases resulting from both NSCLC and SCLC are susceptible to systemic chemotherapy, with cerebral response rates similar to primary tumor responses, even in second-line treatment. Clinical conditions such as a chemotherapy-sensitive primary tumor, no prior chemotherapy, or the presence of systemic metastases should indicate the use of chemotherapy. The brain is rarely the sole site of metastases in lung cancer, and patients receiving cranial irradiation alone often die of extra-cranial tumors rather than cerebral metastases. Chemotherapy can control other disease sites and is generally better tolerated than WBRT. Chemotherapy should be initiated before WBRT because chemotherapy cannot be given for 1 month after WBRT and concomitant WBRT/chemotherapy is more toxic. Combinations of these therapeutic modalities for the management of brain metastases randomized require further testing in phase III studies. Because of the short survival times, the late effects of cranial irradiation such as dementia may be underestimated because they do not usually present until months or years after treatment. Kristensen et al (1) showed response rates of $76 \%$ in primary brain metastases from SCLC but only $43 \%$ in relapsed metastases, similar to other SCLC metastatic sites. Chemotherapy has a clearer therapeutic impact in SCLC than NSCLC. Thus, chemotherapy should be incorporated into the management of brain metastases as part of a multimodal treatment concept.

First-line chemotherapy can be performed in patients with asymptomatic or minor neurological symptoms or other metastatic sites, as well as for relapses after radiotherapy or systemic chemotherapy. The main goal of cytostatic therapy is palliation, with clinical improvement and brief, limited duration of high-dose steroid treatments critical to this palliation. The inclusion of patients with brain metastases from lung cancer in prospective trials of new therapeutic agents or combinations should be pursued.

\section{References}

1. Kristensen CA, Kristjansen PE and Hansen HH: Systemic chemotherapy of brain metastases from small-cell lung cancer: a review. J Clin Oncol 10: 1498-1502, 1992.

2. Wen PY, McLaren Black P and Loeffler JS: Metastatic brain cancer. In: Cancer: Principles and Practice of Oncology. 6th edition. De Vita VT Jr, Hellman S and Rosenberg SA (eds). Lippincott Williams \& Wilkins, Philadelphia, PA, pp2655-2670, 1999.

3. Lagerwaard FJ, Levendag PC, Nowak PJCM, et al: Identification of prognostic factors in patients with brain metastases: a review of 1292 patients. Int J Radiat Oncol Biol Phys 43: 795-803, 1999. 
4. Sheenan JP, Sun MH, Kondziolka D, et al: Radiosurgery for non-small cell lung carcinoma metastatic to the brain: long-term outcomes and prognostic factors influencing patient survival time and local tumor control. J Neurosurg 97: 1276-1281, 2002.

5. Stewart DJ, Leavens M, Maor M, et al: Human central nervous system distribution of cis-diamminedichloroplatinum and use as a radiosensitizer in malignant brain tumors. Cancer Res 42 : 2474-2479, 1982

6. Patchell RA, Tibbs PA, Walsh JW, et al: A randomized trial of surgery in the treatment of single metastases to the brain. $\mathrm{N}$ Engl J Med 322: 494-500, 1990.

7. Kihlström L, Karlsson B and Lindquist C: Gamma Knife surgery for cerebral metastases. Implications for survival based on 16 years experience. Stereotact Funct Neurosurg 61: 45-50, 1993

8. Horton J, Baxter DH and Olson KB: The management of metastases to the brain by irradiation and corticosteroids. Am J Roentgenol Radium Ther Nucl Med 111: 334-336, 1971.

9. Fukuoka S, Seo Y, Takanashi M, et al: Radiosurgery of brain metastases with the Gamma Knife. Stereotact Funct Neurosurg 66: 193-200, 1996

10. Siegers HP: Chemotherapy for brain metastases: recent developments and clinical considerations. Cancer Treat Rev 17: 63-76, 1990

11. Lesser GJ: Chemotherapy of cerebral metastases from solid tumors. Neurosurg Clin N Am 7: 527-536, 1996.

12. Stanley K and Stjernsward J: Lung cancer - a worldwide health problem. Chest 96: S1-S5, 1989.

13. Non-Small Cell Lung Cancer Collaborative Group: Chemotherapy in non-small cell lung cancer: a meta-analysis using updated data on individual patients from 52 randomised clinical trials. BMJ 311: 899-909, 1995

14. Schiller JH, Harrington D, Belani CP, et al: Eastern Cooperative Oncology Group. Comparison of four chemotherapy regimens for advanced non-small cell lung cancer. New Engl J Med 346: 92-98, 2002

15. Cotto C, Berille J, Souquet PJ, et al: A phase II trial of fotemustine and cisplatin in central nervous system metastases from non-small cell lung cancer. Eur J Cancer 32: 69-71, 1996.

16. Malacarne P, Santini A and Maestri A: Response of brain metastases from lung cancer to systemic chemotherapy with carboplatin and etoposide. Oncology 53: 210-213, 1996.

17. Minotti V, Crinò L, Meacci ML, et al: Chemotherapy with cisplatin and teniposide for cerebral metastases in non-small cell lung cancer. Lung Cancer 20: 93-98, 1998.

18. Franciosi V, Cocconi G, Michiara M, et al: Front-line chemotherapy with cisplatin and etoposide for patients with brain metastases from breast carcinoma, non-small cell lung carcinoma, or malignant melanoma: a prospective study. Cancer 85 : 1599-1605, 1999.

19. Fujita A, Ohkubo T, Hoshino H, et al: Phase II study of cisplatin, ifosfamide, and irinotecan with rhG-CSF support in patients with stage IIIb and IV non-small cell lung cancer. Br J Cancer 89: 1008-1012, 2003.

20. Robinet G, Thomas P, Breton JL, et al: Results of a phase III study of early versus delayed whole brain radiotherapy with concurrent cisplatin and vinorelbine combination in inoperable brain metastasis of non-small cell lung cancer: Groupe Francais de Pneumo-Cancérologie (GFPC) Protocol 95-1. Ann Oncol 12 $59-67,2001$

21. Bernardo G, Cuzzoni Q, Strada MR, et al: First-line chemotherapy with vinorelbine, gemcitabine, and carboplatin in the treatment of brain metastases from non-small cell lung cancer: a phase II study. Cancer Invest 20: 293-302, 2002.

22. Cortes J, Rodriguez J, Aramendia JM, et al: Front-line paclitaxel/ cisplatin-based chemotherapy in brain metastases from nonsmall cell lung cancer. Oncology 64: 28-35, 2003.

23. Rusch V, Baselga J, Cordon-Cardo C, et al: Differential expression of the epidermal growth factor receptor and its ligands in primary non-small cell lung cancers and adjacent benign lung. Cancer Res 53: 2379-2385, 1993.

24. Volm M, Rittgen W and Drings P: Prognostic value of ERBB-1, VEGF, cyclin A, FOS, JUN and MYC in patients with squamous cell lung carcinomas. Br J Cancer 77: 663-669, 1998.

25. Lawrence DS and Niu J: Protein kinase inhibitors: the tyrosinespecific protein kinases. Pharmacol Ther 77: 81-114, 1998.

26. Fukuoka M, Yano S, Giaccone G, et al: Multi-institutional randomized phase II trial of gefitinib for previously treated patients with advanced non-small cell lung cancer (The IDEAL 1 Trial). J Clin Oncol 21: 2237-2246, 2003.
27. Kris MG, Natale RB, Herbst RS, et al: Efficacy of gefitinib, an inhibitor of the epidermal growth factor receptor tyrosine kinase, in symptomatic patients with non-small cell lung cancer. A randomized trial. JAMA 290: 2149-2158, 2003.

28. Tsao MS, Sakurada A, Cutz JC, et al: Erlotinib in lung cancer: molecular and clinical predictors of outcome. N Engl J Med 353: 133-144, 2005.

29. Cappuzzo F, Hirsch FR, Ross E, et al: Epidermal growth factor receptor gene and protein and gefitinib sensitivity in non-small cell lung cancer. J Natl Cancer Inst 97: 643-655, 2005.

30. Paez JG, Janne PA, Lee JC, et al: EGFR mutations in lung cancer: correlation with clinical response to gefitinib therapy. Science 304: 1497-1500, 2004.

31. Eberhard DA, Johnson BE, Amler LC, et al: Mutations in the epidermal growth factor receptor and in KRAS are predictive and prognostic indicators in patients with non-small cell lung cancer treated with chemotherapy alone and in combination with erlotinib. J Clin Oncol 23: 5900-5909, 2005.

32. Chiu CH, Tsai CM, Chen YM, et al: Gefitinib is active in patients with brain metastases from non-small cell lung cancer and response is related to skin toxicity. Lung Cancer 47: 129-138, 2005.

33. Wu C, Li YL, Wang ZM, et al: Gefitinib as palliative therapy for lung adenocarcinoma metastatic to the brain. Lung Cancer 57: 359-364, 2007

34. Ceresoli GL, Cappuzzo F, Gregorc V, et al: Gefitinib in patients with brain metastases from non-small cell lung cancer: a prospective trial. Ann Oncol 15: 1042-1047, 2004.

35. Antoniou D, Kyprianou K, Stathopoulos GP, et al: Response to radiotherapy in brain metastases and survival of patients with non-small cell lung cancer. Oncol Rep 14: 733-736, 2005.

36. Nieder $C$, Niewald $M$ and Hagen T: Brain metastases in bronchial and breast carcinoma: differences in metastatic behavior and prognosis (German). Radiologe 35: 816-821, 1995.

37. Shimato S, Mitsudomi T, Kosaka T, et al: EGFR mutations in patients with brain metastases from lung cancer: association with the efficacy of gefitinib. Neuro Oncol 8: 137-144, 2006.

38. Yokouchi H, Yamazaki K, Kinoshita I, et al: Clinical benefit of readministration of gefitinib for initial gefitinib-responders with non-small cell lung cancer. BMC Cancer 7: 51, 2007.

39. Sakai M, Ishikawa S, Ito $\mathrm{H}$, et al: Carcinomatous meningitis from non-small cell lung cancer responding to gefitinib. Int J Clin Oncol 11: 243-245, 2006.

40. Kim MK, Lee KH, Lee JK, et al: Gefitinib is also active for carcinomatous meningitis in NSCLC. Lung Cancer 50: 265-269, 2005.

41. Lai CS, Boshoff C, Falzon M and Lee SM: Complete response to erlotinib treatment in brain metastases from recurrent NSCLC Thorax 61: 91, 2006.

42. Popat S, Hughes S, Papadopoulos P, et al: Recurrent responses to non-small cell lung cancer brain metastases with erlotinib. Lung Cancer 56: 135-137, 2007.

43. Chang JW, Chou CL, Huang SF, et al: Erlotinib response of EGFR-mutant gefitinib-resistant non-small cell lung cancer. Lung Cancer 58: 414-417, 2007.

44. Gounant V, Wislez M, Poulot V, et al: Subsequent brain metastasis responses to epidermal growth factor receptor tyrosine kinase inhibitors in a patient with non-small cell lung cancer. Lung Cancer 58: 425-428, 2007.

45. Fekrazad MH, Ravindranathan M and Jones DV Jr: Response of intracranial metastases to erlotinib therapy. J Clin Oncol 25: 5024-5026, 2007.

46. Von Pawel J, Wagner H, Duell T and Poellinger B: Erlotinib in patients with previously irradiated, recurrent brain metastases from non-small cell lung cancer: two case reports. Onkologie 31: 123-126, 2008

47. Altavilla G, Arrigo C, Santarpia MC, et al: Erlotinib therapy in a patient with non-small cell lung cancer and brain metastases. J Neurooncol 90: 31-33, 2008

48. Ruppert AM, Beau-Faller M, Neuville A, et al: EGFR-TKI and lung adenocarcinoma with CNS relapse: interest of molecular follow-up. Eur Respir J 33: 436-440, 2009.

49. Pao W and Miller VA: Epidermal growth factor receptor mutations, small-molecule kinase inhibitors, and non-small cell lung cancer: current knowledge and future directions. J Clin Oncol 23: 2556-2568, 2005.

50. Baker SD, Wirth M, Statkevich P, et al: Absorption, metabolism and excretion of $14 \mathrm{C}$-temozolomide following oral administration to patients with advanced cancer. Clin Cancer Res 5: 309-317, 1999. 
51. Ostermann S, Csajka C, Buclin T, et al: Plasma and cerebrospinal fluid population pharmacokinetics of temozolomide in malig nant glioma patients. Clin Cancer Res 10: 3728-3736, 2004.

52. Giorgio CG, Giuffrida D, Pappalardo A, et al: Oral temozolomide in heavily pre-treated brain metastases from non-small cell lung cancer: phase II study. Lung Cancer 50: 247-254, 2005.

53. Kouroussis C, Vamvakas L, Vardakis N, et al: Continuous administration of daily low-dose temozolomide in pretreated patients with advanced non-small cell lung cancer: a phase II study. Oncology 76: 112-117, 2009.

54. Abrey LE, Olson JD, Raizer JJ, et al: A phase II trial of TMZ for patients with recurrent or progressive brain metastases. J Neuro Oncol 53: 259-265, 2001.

55. Christodoulou C, Bafaloukos D, Kosmidis P, et al: Phase II study of temozolomide in heavily pretreated cancer patients with brain metastases. Ann Oncol 12: 249-254, 2001.

56. D'Atri S, Graziani G, Lacal PM, et al: Attenuation of O6methylguanine-DNA methyltransferase activity and mRNA levels by cisplatin and temozolomide in jurkat cells. J Pharmacol Exp Ther 294: 664-671, 2000.

57. Piccioni D, D'Atri S, Papa G, et al: Cisplatin increases sensitivity of human leukemic blasts to triazene compounds. $J$ Chemother 7: 224-229, 1995.

58. Ebert BL, Niemerko E, Shaffer K, et al: Use of temozolomide with other cytotoxic chemotherapy in the treatment of patients with recurrent brain metastases from lung cancer. Oncologist 8: 69-75, 2003.

59. Mangiameli A, Mineo G and Trovato G: Temozolomide (TMZ) in patients with brain metastases from NSCLC in combination with brain metastases from NSCLC in combination with gemcitabine-cisplatin (GEM+CDDP) or gemcitabine-vinorelbine (GEM+VNB). Proc Am Soc Clin Oncol 20: A2797, 2001.

60. Quantin X, Khial F, Reme-Saumon M, et al: Concomitant brain radiotherapy and vinorelbine-ifosfamide-cisplatin chemotherapy in brain metastases of non-small cell lung cancer. Lung Cancer 26: 25-39, 1999

61. Quantin X, Pujol JL, Paris A, et al: Concomitant brain radiotherapy and high-dose ifosfamide in brain relapses of lung cancer. Ann Oncol 8: 911-913, 1997.

62. Ma S, Xu Y, Deng Q and Yu X: Treatment of brain metastasis from non-small cell lung cancer with whole brain radiotherapy and Gefitinib in a Chinese population. Lung Cancer 65: 198-203, 2009.

63. Addeo R, De Rosa C, Faiola V, et al: Phase 2 trial of temozolomide using protracted low-dose and whole-brain radiotherapy for non-small cell lung cancer and breast cancer patients with brain metastases. Cancer 113: 2524-2531, 2008.

64. Cortot $\mathrm{AB}$, Gerinière L, Robinet $\mathrm{G}$, et al: Phase II trial of temozolomide and cisplatin followed by whole brain radiotherapy in non-small cell lung cancer patients with brain metastases: a GLOT-GFPC study. Ann Oncol 17: 1412-1417, 2006.

65. Antonodau D, Paraskevaidis M, Sarris G, et al: Phase II randomized trial of temozolomide and concurrent radiotherapy in patients with brain metastases. J Clin Oncol 20: 3644-3650, 2002.

66. Van de Pol M, van Oosterhout AG, Wilmink JT, et al: MRI in detection of brain metastases at initial staging of small-cell lung cancer. Neuroradiology 38: 207-210, 1996.

67. Seute T, Leffers P, Ten Velde GP and Twijnstra A: Neurologic disorders in 432 consecutive patients with small cell lung carcinoma. Cancer 100: 801-806, 2004

68. Komaki R, Cox JD and Whitson W: Risk of brain metastasis from small cell carcinoma of the lung related to length of survival and prophylactic irradiation. Cancer Treat Rep 65: 811-814, 1981.
69. Arriagada R, Le Chevalier T, Borie F, et al: Prophylactic cranial irradiation for patients with small-cell lung cancer in complete remission. J Natl Cancer Inst 87: 183-190, 1995.

70. Lee JS, Murphy WK, Glisson BS, et al: Primary chemotherapy of brain metastasis in small-cell lung cancer. J Clin Oncol 7: 916-922, 1989

71. Twelves CJ, Souhami RL, Harper PG, et al: The response of cerebral metastases in small cell lung cancer to systemic chemotherapy. Br J Cancer 61: 147-150, 1990

72. Kristjansen PE, Soelberg Sørensen P, Skov Hansen M and Hansen HH: Prospective evaluation of the effect on initial brain metastases from small cell lung cancer of platinum-etoposide based induction chemotherapy followed by an alternating multidrug regimen. Ann Oncol 4: 579-583, 1993.

73. Seute T, Leffers P, Wilmink JT, et al: Response of asymptomatic brain metastases from small-cell lung cancer to systemic firstline chemotherapy. J Clin Oncol 24: 2079-2083, 2006.

74. Postmus PE, Haaxma-Reiche H, Sleijfer DT, et al: High-dose etoposide for central nervous system metastases of small cell lung cancer. Preliminary results. Eur J Respir Dis Suppl 149: 65-71, 1987.

75. Groen HJ, Smit EF, Haaxma-Reiche H and Postmus PE: Carboplatin as second line treatment for recurrent or progressive brain metastases from small cell lung cancer. Eur J Cancer 29: 1696-1699, 1993.

76. Postmus PE, Smit EF, Haaxma-Reiche H, et al: Teniposide for brain metastases of small-cell lung cancer: a phase II study. European Organization for Research and Treatment of Cancer Lung Cancer Cooperative Group. J Clin Oncol 13: 660-665, 1995.

77. Schütte W, Manegold C, von Pawel JV, et al: Topotecan - a new treatment option in the therapy of brain metastases of lung cancer. Front Radiat Ther Oncol 33: 354-363, 1999.

78. Postmus PE, Haaxma-Reiche H, Smit EF, et al: Treatment of brain metastases of small-cell lung cancer: comparing teniposide and teniposide with whole-brain radiotherapy - a phase III study of the European Organization for the Research and Treatment of Cancer Lung Cancer Cooperative Group. J Clin Onol 18: 3400-3408, 2000

79. Korfel A, Oehm C, von Pawel J, et al: Response to topotecan of symptomatic brain metastases of small-cell lung cancer also after whole-brain irradiation. a multicentre phase II study. Eur J Cancer 38: 1724-1729, 2002.

80. Chen G, Huynh M, Chen A, et al: Chemotherapy for metastases in small-cell lung cancer. Clin Lung Cancer 9: 35-38, 2008.

81. Régina A, Demeule M, Laplante A, et al: Multidrug resistance in brain tumors: roles of the blood brain barrier. Cancer Metastasis Rev 20: 13-25, 2001

82. Postmus PE and Smit EF: Chemotherapy for brain metastases of lung cancer: a review. Ann Oncol 10: 753-759, 1999.

83. Bunn PA Jr, Nugent JL and Matthews MJ: Central nervous system metastases in small cell bronchogenic carcinoma. Semin Oncol 5: 314-322, 1978.

84. Neijstrom ES, Capizzi RL, Rudnick SA, et al: High-dose methotrexate in small cell lung cancer. Lack of efficacy in preventing CNS relapse. Cancer 51: 1056-1061, 1983.

85. Van den Bent MJ: The role of chemotherapy in brain metastases. Eur J Cancer 39: 2114-2120, 2003

86. McCune JS, Hawke RL, Le Cluyse EL, et al: In vivo and in vitro induction of human cytochrome P4503A4 by dexamethasone. Clin Pharmacol Ther 68: 356-366, 2000.

87. Yap KY, Chui WK and Chan A: Drug interactions between chemotherapeutic regimens and antiepileptics. Clin Ther 30: 1385-1407, 2008 